\title{
Differential regulation of adaptive and apoptotic unfolded protein response signalling by cytokine-induced nitric oxide production in mouse pancreatic beta cells
}

\author{
J. Y. Chan • G. J. Cooney • T. J. Biden • D. R. Laybutt
}

Received: 10 January 2011 /Accepted: 9 March 2011 / Published online: 7 April 2011

(C) Springer-Verlag 2011

\begin{abstract}
Aims/hypothesis Pro-inflammatory cytokines such as IL$1 \beta$, IFN- $\gamma$ and TNF- $\alpha$ may contribute to pancreatic beta cell destruction in type 1 diabetes. A mechanism requiring nitric oxide, which is generated by inducible nitric oxide synthase (iNOS), in cytokine-induced endoplasmic reticulum (ER) stress and apoptosis has been proposed. Here, we tested the role of nitric oxide in cytokine-induced ER stress and the subsequent unfolded protein response (UPR) in beta cells.

Methods Isolated islets from wild-type and iNos (also known as Nos2) knockout $\left(\mathrm{iNos}^{-/-}\right)$mice, and MIN6 beta cells were incubated with IL- $1 \beta$, IFN- $\gamma$ and TNF- $\alpha$ for $24-48$ h. $N^{\mathrm{G}}$-methyl-L-arginine was used to inhibit nitric oxide production in MIN6 cells. Protein levels and gene expression were assessed by western blot and realtime RT-PCR.

Results In islets and MIN6 cells, inhibition of nitric oxide production had no effect on the generation of ER stress by cytokines, as evidenced by downregulation of Serca $2 b$ (also known as Atp2a2) mRNA and increased phosphorylation of PKR-like ER kinase, Jun N-terminal kinase (JNK) and eukaryotic translation initiation factor $2 \alpha$ subunit. However, nitric oxide regulated the pattern of UPR signalling, which delineates the cellular decision to adapt to ER stress or to undergo apoptosis. Inhibition of nitric oxide production led to reduced expression of pro-apoptotic UPR
\end{abstract}

Electronic supplementary material The online version of this article (doi:10.1007/s00125-011-2139-z) contains supplementary material, which is available to authorised users.

J. Y. Chan · G. J. Cooney · T. J. Biden • D. R. Laybutt $(\bowtie)$ Garvan Institute of Medical Research, St Vincent's Hospital, 384 Victoria St,

Darlinghurst, NSW 2010, Australia

e-mail: r.laybutt@garvan.org.au markers, Chop (also known as Ddit3), Atf3 and Trib3. In contrast, adaptive UPR markers (chaperones, foldases and degradation enhancers) were increased. Further analysis of mouse islets showed that cytokine-induced Chop and Atf3 expression was also dependent on JNK activity.

Conclusions/interpretation The mechanism by which cytokines induce ER stress in mouse beta cells is independent of nitric oxide production. However, nitric oxide may regulate the switch between adaptive and apoptotic UPR signalling.

Keywords Apoptosis - Cytokines - Endoplasmic reticulum stress $\cdot$ Islets $\cdot$ Nitric oxide $\cdot$ Pancreatic beta cell $\cdot$ Type 1 diabetes

$\begin{array}{ll}\text { Abbreviations } \\ \text { ATF } & \text { Activating transcription factor } \\ \text { CHOP } & \text { C/EBP homologous protein } \\ \text { EIF2 } \alpha & \text { Eukaryotic translation initiation factor } 2 \alpha \text { subunit } \\ \text { ER } & \text { Endoplasmic reticulum } \\ \text { ERAD } & \text { ER-associated degradation } \\ \text { iNOS } & \text { Inducible nitric oxide synthase } \\ \text { IRE1 } & \text { Inositol-requiring enzyme 1 } \\ \text { JNK } & \text { Jun N-terminal kinase } \\ \text { LMA } & N^{\mathrm{G}} \text {-methyl-L-arginine } \\ \text { PERK } & \text { PKR-like ER kinase } \\ \text { UPR } & \text { Unfolded protein response } \\ \text { XBP1 } & \text { X-box binding protein 1 }\end{array}$

\section{Introduction}

Type 1 diabetes results from the autoimmune destruction of pancreatic islet beta cells. Pro-inflammatory cytokines, such as IL- $1 \beta$, IFN- $\gamma$ and TNF- $\alpha$ are suspected mediators of 
beta cell death in type 1 diabetes, although the mechanisms remain unclear [1-3]. Much recent attention has focussed on the potential involvement of stress within the organelle endoplasmic reticulum (ER) in cytokine-mediated beta cell death [4-15].

The ER is involved in folding, processing and trafficking of newly synthesised secretory and membrane proteins. Protein synthesis and secretion are precisely coupled with the capacity of the ER to perform these tasks. Optimal function of the ER is facilitated by a variety of chaperones and foldases, which ensure successful production of maturely folded proteins. Components of the ERassociated degradation (ERAD) pathway facilitate the targeting, extraction and proteasomal degradation of misfolded proteins. In ER stress, various insults disrupt ER function, leading to the accumulation of misfolded proteins in the ER $[8,16,17]$. The ER transmembrane signalling proteins PKR-like ER kinase (PERK), activating transcription factor (ATF) 6 and inositol-requiring enzyme 1 (IRE1) $\alpha$ sense ER stress and coordinate the unfolded protein response (UPR). The primary goal of the UPR is to restore ER homeostasis via mechanisms that include transcriptional activation of genes encoding ER chaperones and foldases to augment protein folding activity, and via the ERAD machinery to increase proteasomal degradation of misfolded proteins. Should these adaptive processes fail to attenuate ER stress, apoptosis is triggered through various UPR signalling pathways, including transcriptional activation of the Chop (also known as Ddit3) gene and IRE1-mediated activation of Jun N-terminal kinase (JNK) [8, 16-19]. The mechanisms that control this switch from UPR for survival to UPR for death signalling are not completely understood.

Beta cells, with their heavy engagement in protein synthesis and secretory activity, are particularly sensitive to ER stress, with severe or prolonged episodes leading to beta cell apoptosis $[8,10,19-21]$. A potential role for ER stress in type 1 diabetes was suggested in studies showing that pro-inflammatory cytokines could induce ER stress in cultured beta cells, possibly via the generation of nitric oxide [4-6]. It is proposed that nitric oxide acts as a messenger molecule for cytokine-mediated Serca2b (also known as Atp2a2) downregulation, depletion of ER calcium stores and generation of ER stress, which ultimately leads to beta cell death. In line with this, increasing ER calcium content or depletion of the ER stress-inducible pro-apoptotic transcription factor C/EBP homologous protein $(\mathrm{CHOP})$ at least partially protects beta cells against nitric oxide-mediated apoptosis [4]. Cytokine-induced ER stress in beta cells is characterised by an atypical UPR notable for suppression of the adaptive response [22]. Thus, while pro-apoptotic UPR signalling is readily activated by cytokines, the expression of ER chaperones is reduced, principally due to the action of IFN- $\gamma[22]$. It has been proposed that this decrease in defence mechanisms against ER stress contributes to the heightened susceptibility of beta cells to cytokine-mediated apoptosis.

Here, we investigated the influence of nitric oxide production on cytokine-induced ER stress in beta cells. We demonstrate that while nitric oxide is not required for the generation of ER stress by cytokines, it plays an important role in subsequent ER stress signalling by differentially regulating adaptive and pro-apoptotic components of the UPR. This ability of nitric oxide to regulate the pattern of UPR signalling may provide a mechanism for the decision of beta cells to undergo apoptosis rather than to adapt to ER stress and survive the cytokine attack.

\section{Methods}

Cell culture and treatments Cells of the mouse insulinoma cell line MIN6 were passaged in DMEM (Invitrogen, Carlsbad, CA, USA) containing $25 \mathrm{mmol} / 1$ glucose, $10 \mathrm{mmol} / 1 \mathrm{HEPES}, 10 \%$ (vol./vol.) FCS, $100 \mathrm{U} / \mathrm{ml}$ penicillin and $100 \mu \mathrm{g} / \mathrm{ml}$ streptomycin. Cells were seeded at either $2 \times 10^{5}$ in $0.5 \mathrm{ml}$ per well in a 24 -well plate or at $8 \times 10^{5}$ in $2 \mathrm{ml}$ per well in a six-well plate. After seeding, cells were treated for $24 \mathrm{~h}$ with $100 \mathrm{U} / \mathrm{ml} \mathrm{IL}-1 \beta, 250 \mathrm{U} / \mathrm{ml}$ IFN- $\gamma$ and $100 \mathrm{U} / \mathrm{ml}$ TNF- $\alpha$ (R\&D Systems, Minneapolis, $\mathrm{MN}, \mathrm{USA}) . \quad N^{\mathrm{G}}$-methyl-L-arginine (LMA) $(1 \mathrm{mmol} / \mathrm{l}$; Sigma, St Louis, MO, USA) was used to inhibit nitric oxide production. Nitric oxide was measured in culture media using Griess reagent [23].

Islet isolation and culture iNos (also known as Nos2) wildtype mice (C57BL/6J) and iNos knockout mice (C57BL/6Nos2 $2^{\text {tmlLau }}$ colony, referred to as $i \mathrm{Nos}^{-/}$mice) were bred in-house using animals originally from The Jackson Laboratories (Bar Harbor, ME, USA). Islets were isolated by dissociation of pancreases (liberase RI; Roche Diagnostics, Castle Hill, NSW, Australia), followed by gradient centrifugation at $1,360 \times \mathrm{g}$ for $20 \mathrm{~min}$ (Ficoll-Paque PLUS gradient; GE Healthcare Bio-Sciences, Uppsala, Sweden) and handpicking under a stereomicroscope. Procedures were approved by the Garvan Institute/St Vincent's Hospital Animal Experimentation Ethics Committee, following guidelines issued by the National Health and Medical Research Council of Australia. Islets were cultured at $37^{\circ} \mathrm{C}$ in RPMI 1640 medium supplemented with $0.2 \mathrm{mmol} / \mathrm{l}$ glutamine, $10 \%$ (vol./vol.) heat-inactivated fetal bovine serum, $100 \mathrm{U} / \mathrm{ml}$ penicillin and $100 \mu \mathrm{g} / \mathrm{ml}$ streptomycin. Islets were treated for 24 or $48 \mathrm{~h}$ with $100 \mathrm{U} / \mathrm{ml}$ IL- $1 \beta, 250 \mathrm{U} / \mathrm{ml}$ IFN- $\gamma$ and $100 \mathrm{U} / \mathrm{ml}$ TNF- $\alpha$ (R\&D Systems, Minneapolis, MN, USA). JNK inhibitor II (20 $\mu \mathrm{mol} / 1$ SP600125; Merck, Kilsyth, VIC, Australia) was used to inhibit JNK activity in islets isolated from $\mathrm{C} 57 \mathrm{BL} / 6 \mathrm{~J}$ mice. 
Cell death assay Cell death was measured with a cell death detection ELISA (Roche Diagnostics) [24], which measures cytoplasmic histone-associated DNA fragments. Islets were lysed in $0.2 \mathrm{ml}$ of the supplied lysis buffer, incubated for $30 \mathrm{~min}$ at room temperature and the lysate was spun at $200 \times \mathrm{g}$ for $10 \mathrm{~min}$. The ELISA assay was then performed according to manufacturers' instructions.

Western blotting Total protein levels from cell and islet extracts were measured (protein assay; Bio-Rad Laboratories, Hercules, CA, USA). Protein $(20-50 \mu \mathrm{g})$ was resolved on NuPage SDS-PAGE gels (Invitrogen) and transferred to polyvinylidine difluoride membrane. Membranes were incubated in primary antibodies for $1-2 \mathrm{~h}$ at room temperature or overnight at $4{ }^{\circ} \mathrm{C}$. The following antibodies were used $(1: 1,000$ dilution unless otherwise indicated): (1) CHOP (sc-575) and total eukaryotic translation initiation factor $2 \alpha$ subunit (EIF2 $\alpha$ ) (sc-11386) (Santa Cruz Biotechnology, Santa Cruz, CA, USA); (2) phospho-PERK (Thr980, 16 F8, 3179), phospho-EIF2 $\alpha$ (Ser51, 9721), phospho-JNK (Thr183/ Tyr185, 9251), phosphor-c-JUN (Ser73, 9164S) and total JNK (9252) (Cell Signaling Technology, Danvers, MA, USA). Equal loading of protein between lanes was confirmed by subsequent $\beta$-actin immunoblots (1:5,000; Sigma). After incubation with horseradish peroxidase-conjugated sheep anti-mouse or donkey anti-rabbit (1:5,000; Jackson ImmunoResearch, West Grove, PA, USA) antibody for $1 \mathrm{~h}$ at room temperature, immunodetection was performed by chemiluminescence (PerkinElmer, Wellesley, MA, USA or Millipore, Billerica, MA, USA). Densitometry was performed using a software package (Quantity One; Bio-Rad).

RNA analysis Total RNA was extracted from islets or MIN6 cells [25] and cDNA was synthesised using a kit (QuantiTect Reverse Transcription; Qiagen, Doncaster, VIC, Australia) according to manufacturer's instructions. Real-time PCR was performed using Power SYBR Green PCR Master Mix (Applied Biosystems, Foster City, CA, USA) on a real-time PCR System (7900HT; Applied Biosystems). The value obtained for each specific product was normalised to a control gene (cyclophilin A) and expressed as fold-change of the value in control extracts.

Xbpl splicing Total RNA was extracted from islets and reverse-transcribed as above. $X b p 1$ cDNA was amplified by PCR and digested with PstI, which cuts unprocessed Xbpl cDNA into fragments [26]. Processed (activated) Xbp1 cDNA lacks the restriction site and remains intact. Processed (intact) and unprocessed (cut) $\mathrm{Xbpl}$ were quantified by densitometry. The value obtained for processed $X b p 1$ was expressed as a ratio of the total (processed+unprocessed) $X b p l$ mRNA level for each sample. These ratios are expressed as foldchange of the ratio compared with wild-type control islets.
Statistical analysis All results are presented as means \pm SEM. Statistical analyses were performed using unpaired Student's $t$ test or one-way ANOVA.

\section{Results}

Cytokines induce ER stress independently of nitric oxide formation in MIN6 cells We first investigated the influence of nitric oxide on the induction of ER stress by cytokines in MIN6 beta cells. In control MIN6 cells, treatment with the combination of cytokines (IL- $1 \beta+$ IFN- $\gamma+$ TNF- $\alpha$ ) for $24 \mathrm{~h}$ induced nitric oxide formation (Fig. 1a) and ER stress as evidenced by increased phosphorylation of PERK (Fig. 1b, c), JNK1 (46 kDa) (Fig. 1b, d), JNK2 (54 kDa) (Fig. 1b, e) and EIF2 $\alpha$ (Fig. 1b, f). Treatment of MIN6 cells with LMA, a nitric oxide synthase inhibitor, blocked cytokine-induced formation of nitric oxide (Fig. 1a). However, inhibition of nitric oxide formation had no effect on the ability of cytokines to induce ER stress; cytokine-mediated increases in PERK, JNK $1 / 2$ and EIF $2 \alpha$ phosphorylation were similar in control and LMA-treated MIN6 cells (Fig. 1b-f). Thus, cytokines retained the ability to induce ER stress even after inhibition of nitric oxide formation in MIN6 cells, suggesting that the presence of nitric oxide is not required for the generation of ER stress by cytokines. We next tested the influence of nitric oxide levels on downstream UPR signalling by examining the abundance of CHOP, a proapoptosis transcription factor primarily induced through the PERK/EIF2 $\alpha$ pathway, although IRE $1 \alpha / \mathrm{X}$-box binding protein 1 (XBP1) and ATF6 pathways can also contribute [20]. Cytokine-induced CHOP levels were significantly lower in LMA-treated MIN6 cells than in control-treated cells (Fig. 1b, g). This suggests that nitric oxide is partially required for induction of CHOP production by cytokines in beta cells. These findings raise the possibility that nitric oxide requirements for the induction and sensing of ER stress may differ from subsequent $\mathrm{CHOP}$ induction via downstream UPR signalling.

Nitric oxide production and abundance of ER stress markers in response to different combinations of cytokines in MIN6 cells We next examined MIN6 cell responses to different combinations of cytokines. Nitric oxide production was unchanged in MIN6 cells treated for $24 \mathrm{~h}$ with IL$1 \beta$, IFN- $\gamma$ or TNF- $\alpha$ alone (Fig. 2a). Similarly, the combination of IL- $1 \beta+\mathrm{TNF}-\alpha$ and IFN- $\gamma+\mathrm{TNF}-\alpha$ failed to augment nitric oxide production (Fig. 2a). In contrast, increased nitric oxide production was observed after treatment of MIN6 cells with the combination of IL-1 $\beta+$ IFN- $\gamma$ as well as with all three cytokines (Fig. 2a). ER stress was evidenced in cytokine-treated MIN6 cells both in the absence and in the presence of augmented nitric oxide 

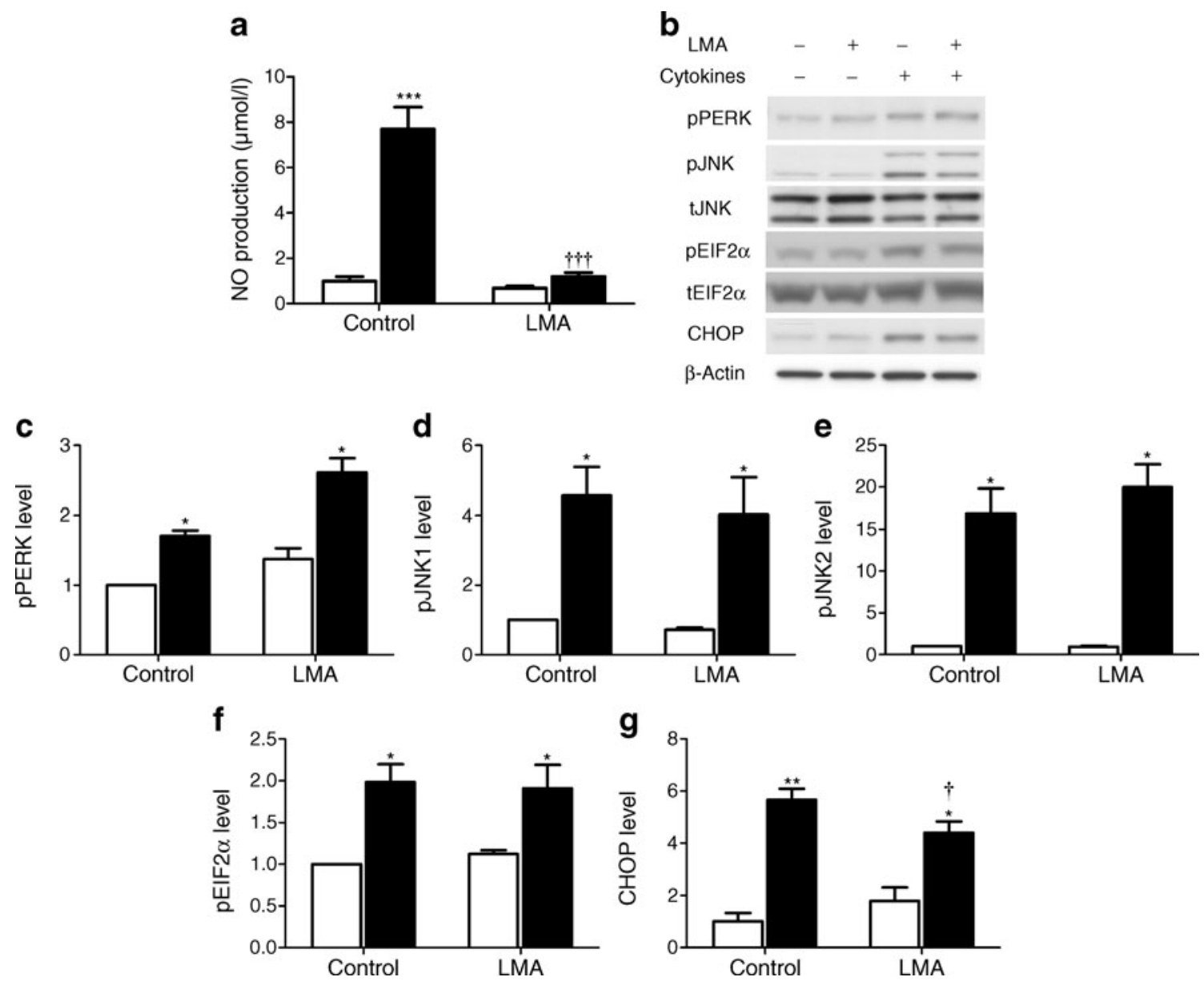

Fig. 1 Effects of iNOS inhibition on cytokine-mediated changes in nitric oxide formation and expression of ER stress markers in MIN6 beta cells. MIN6 cells were incubated for $24 \mathrm{~h}$ in the absence or presence of LMA $(1 \mathrm{mmol} / \mathrm{l})$ as indicated, in combination with absence (white bars) or presence (black bars) of IL-1 $\beta(100 \mathrm{U} / \mathrm{ml})$, IFN- $\gamma(250 \mathrm{U} / \mathrm{ml})$ and TNF- $\alpha(100 \mathrm{U} / \mathrm{ml})$. a Levels of nitric oxide in medium were determined by Griess reaction. b Western blot was performed on protein extracts for PERK, JNK and EIF2 $\alpha$ phosphor-

ylation (p) and CHOP. Total (t) JNK, EIF $2 \alpha$ and $\beta$-actin served as loading controls. Representative images are shown. Abundance of (c) pPERK, (d) pJNK1 (46 kDa), (e) pJNK2 (54 kDa), (f) pEIF2 $\alpha$ and (g) $\mathrm{CHOP}$ was quantified by densitometry and expressed as fold-change compared with control. All results are mean \pm SEM determined from at least three experiments; ${ }^{*} p<0.05,{ }^{* *} p<0.01$ and $* * * p<0.001$ for cytokine effect in LMA and control-treated MIN6 cells; ${ }^{\dagger} p<0.05$ and ${ }^{\dagger \dagger} p<0.001$ for LMA-treated vs control-treated MIN6 cells

production. Thus phosphorylation of PERK, JNK1/2 and EIF $2 \alpha$ was increased in cells with unchanged or increased nitric oxide production (Fig. 2b, electronic supplementary material $[E S M]$ Fig. 1a-d). This further illustrates the independence of cytokine-induced ER stress from nitric oxide production. With regard to downstream cytokine-mediated UPR signalling, CHOP was markedly induced in MIN6 cells with increased nitric oxide production, whereas it was lower in MIN6 cells that did not produce nitric oxide (Fig. 2b, ESM Fig. 1e). These findings provide further support for a role of cytokine-mediated nitric oxide production in the regulation of pro-apoptotic CHOP production.

Cytokines induce ER stress in islets from wild-type and $\mathrm{iNos}^{--}$mice To investigate the role of nitric oxide in cytokine-induced ER stress in primary beta cells, we used islets isolated from mice that selectively lack the gene

encoding inducible nitric oxide synthase (iNOS) $\left(\mathrm{iNos}^{-/}\right.$ mice). In wild-type (C57BL/6J) mouse islets, treatment with the combination of cytokines (IL- $1 \beta+$ IFN- $\gamma+$ TNF- $\alpha$ ) for $24 \mathrm{~h}$ led to expected increases in nitric oxide formation (Fig. 3a) and cell death (Fig. 3b). This was associated with the induction of ER stress as evidenced by increased phosphorylation of PERK (Fig. 3c, d), JNK1 (Fig. 3c, e), JNK2 (Fig. 3c, f) and EIF2 $\alpha$ (Fig. 3c, g). In islets from $\mathrm{iNos}^{-/}$mice, cytokine-induced nitric oxide formation (Fig. 3a) and cell death (Fig. 3b) were prevented. However, cytokine-mediated ER stress was preserved in islets from $\mathrm{iNos}^{-/}$mice; the cytokine-mediated increase in PERK, JNK1 and EIF2 $\alpha$ phosphorylation in $i \mathrm{Nos}^{-/}$islets was similar to that observed in wild-type islets (Fig. 3c-e, g). On the other hand, JNK2 phosphorylation was significantly lower in $\mathrm{iNos}^{-1-}$ islets than that observed in wild-type islets (Fig. 3c, f), a finding consistent with previous observations 
a

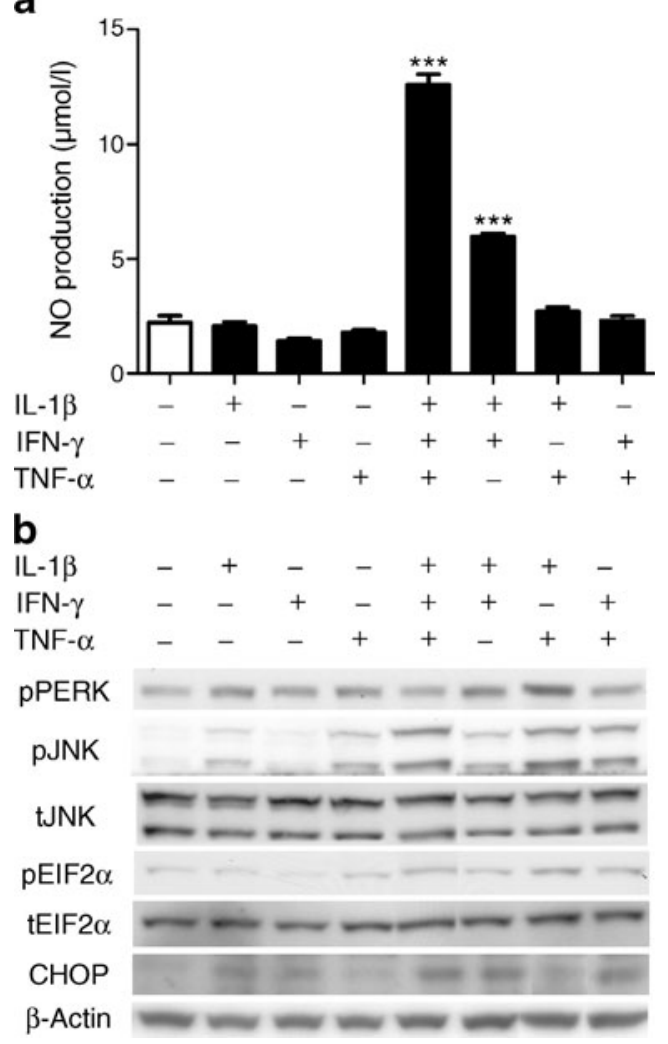

Fig. 2 Relationship between nitric oxide production and abundance of ER stress markers in response to different combinations of cytokines in MIN6 beta cells. MIN6 cells were incubated for $24 \mathrm{~h}$ in the absence or presence of different combinations of IL- $1 \beta(100 \mathrm{U} / \mathrm{ml})$, IFN- $\gamma(250 \mathrm{U} / \mathrm{ml})$ and TNF- $\alpha$ $(100 \mathrm{U} / \mathrm{ml})$ as indicated. a Levels of nitric oxide in medium were determined by Griess reaction. b Western blot was performed on protein extracts for PERK, JNK and EIF2 $\alpha$ phosphorylation (p) and CHOP. Total (t) JNK, EIF $2 \alpha$ and $\beta$-actin served as loading controls. Representative images are shown. $* * * p<0.001$ for cytokine effect

[27]. However, the incremental increase in JNK2 phosphorylation attributable to cytokines was similar between the genotypes (Fig. 3c, f). Also increased by cytokines in wild-type islets were levels of the spliced (activated) form of Xbpl mRNA (Fig. 3i). In contrast to the ER stress markers described above, the cytokine-mediated increase in spliced Xbpl mRNA was significantly higher in $\mathrm{iNos}^{-/-}$ islets than in wild-type islets (Fig 3i). Taken together, these data indicate that iNOS production and/or nitric oxide formation are not required for the generation of ER stress in mouse islets. However, nitric oxide production may contribute to potentiation of JNK2 phosphorylation and, in an opposing role, may inhibit the further splicing (activation) of Xbpl mRNA by cytokines.

We also examined the influence of nitric oxide on cytokine-induced $\mathrm{CHOP}$ protein production in mouse islets. In wild-type islets, $\mathrm{CHOP}$ protein abundance was increased by threefold (Fig. 3c, h). In contrast, cytokines failed to induce the production of $\mathrm{CHOP}$ protein in islets from $\mathrm{iNos}^{-/}$mice (Fig. 3c, h), indicating that nitric oxide is required for the production of $\mathrm{CHOP}$ protein in mouse islets in response to cytokines.

Time-dependent changes in mRNA levels of adaptive and pro-apoptotic UPR markers in cytokine-stimulated islets from wild-type and $\mathrm{iNos}^{-1}$ mice We next assessed whether nitric oxide production affected the pattern of cytokinestimulated UPR signalling in islets. The expression of genes involved in pro-apoptotic and adaptive UPR signalling was examined by real-time RT-PCR (details on oligonucleotide primers, see ESM Table 1). Exposure of wild-type islets to cytokines resulted in increased expression of pro-apoptotic genes Chop, Atf3 and Trib3 (Fig. 4a-c). In contrast, these genes were unchanged or induced to a lesser extent by cytokines in islets from $\mathrm{iNos}^{-/-}$mice (Fig. 4a-c). These data indicate that nitric oxide is, at least partially, required for upregulation of pro-apoptotic UPR genes by cytokines in islets.

We evaluated mRNA expression of ER chaperones and folding proteins, which contribute to the adaptive UPR. ER chaperone genes Bip (also known as Hspa5) Grp94 (also known as Hsp90b1) and Orp150 (also known as Hyoul) and foldase genes Erp72 (also known as Pdia4), Fkbp11 and Herpudl were downregulated after 24 and $48 \mathrm{~h}$ of cytokine stimulation in wild-type islets (Fig. 4d-i). In contrast, these genes were unchanged or even increased by cytokines in islets from $\mathrm{iNos}^{-/-}$mice (Fig. $4 \mathrm{~d}-\mathrm{i}$ ). We also tested $p 58$ (also known as Dnajc3) and Edem 1, both of which are transcriptional targets of XBP1 $[28,29]$ involved in ER chaperone activity and in the ERAD pathway, respectively. In $\mathrm{iNos}^{-/}$islets, p58 mRNA expression was protected from the cytokine-mediated downregulation observed in wild-type islets (Fig. 4j). In wild-type islets, Edem 1 was modestly increased after 24 h, but not after $48 \mathrm{~h}$ of cytokine stimulation (Fig. 4k). In $\mathrm{NON}^{-/}$ islets, Edem 1 mRNA level was significantly increased after 24 and $48 \mathrm{~h}$ of cytokine stimulation to a greater extent than in wild-type islets (Fig. 4k). These data imply a causal relationship between nitric oxide production and the suppression of ER stress defence mechanisms in cytokinestimulated beta cells.

Cytokines downregulate Serca2b independently of nitric oxide formation in MIN6 cells and mouse islets Consistent with the notion that cytokines induce ER stress via downregulation of Serca $2 b$ and depletion of ER calcium stores in beta cells [5], Serca2b mRNA levels were reduced by cytokines in MIN6 cells (Fig. 5a) and in islets from wildtype mice (Fig. 5b). Blocking nitric oxide production did not prevent the downregulation of Serca2b; indeed, mRNA levels after cytokine exposure were still significantly reduced in LMA-treated MIN6 cells (Fig. 5a) and in islets from $\mathrm{iNos}^{-/}$ 
a

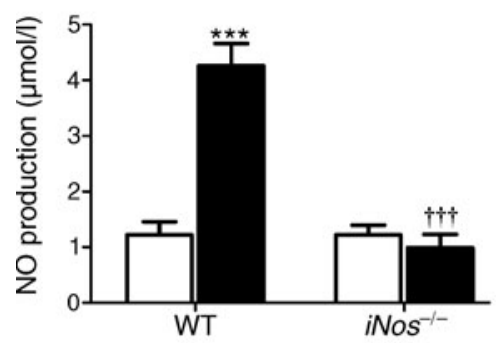

d
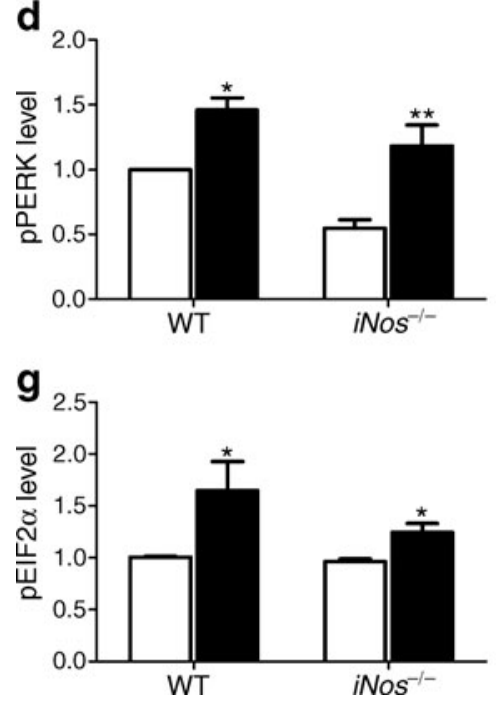

b

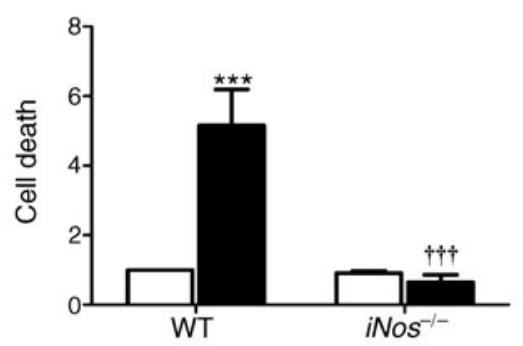

C

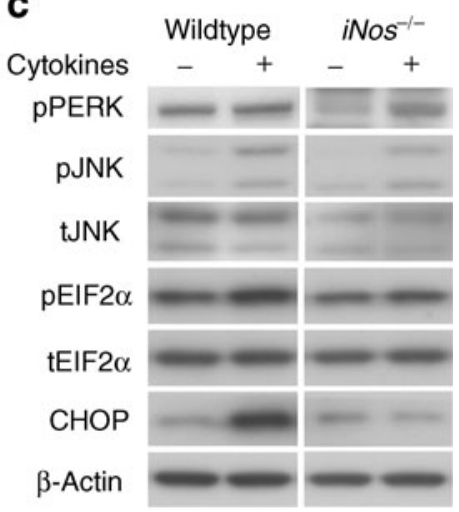

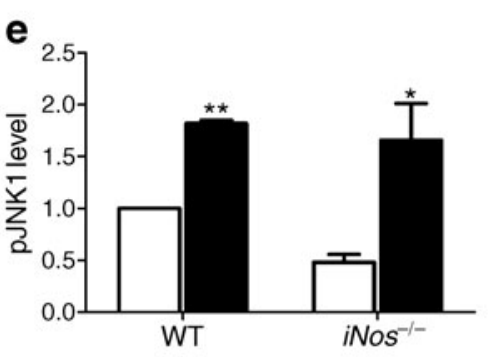

h

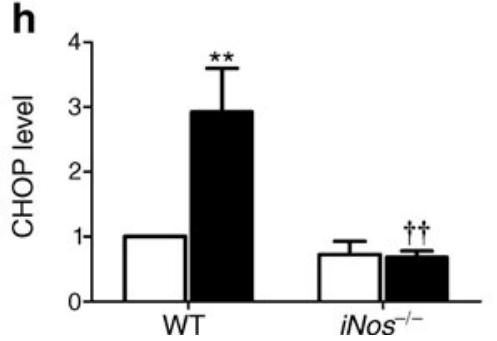

f

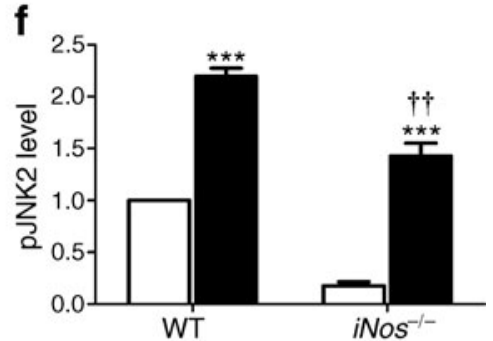

i

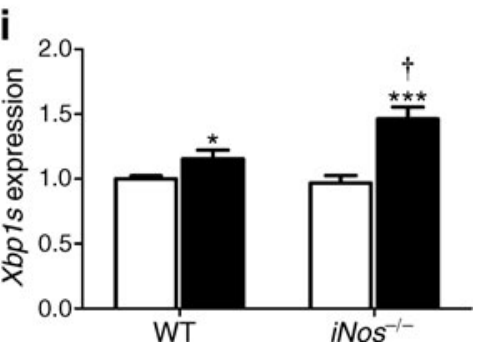

Fig. 3 Effects of $i N o s$ deletion on cytokine-mediated changes in nitric oxide formation, cell death, abundance of ER stress markers and $\mathrm{Xbpl}$ splicing in mouse islets. Isolated islets from wild-type (WT) and $i \mathrm{Nos}^{-1-}$ mice were incubated for $24 \mathrm{~h}$ in the absence (white bars) or presence (black bars) of IL-1 $\beta(100 \mathrm{U} / \mathrm{ml})$, IFN- $\gamma(250 \mathrm{U} / \mathrm{ml})$ and TNF- $\alpha(100 \mathrm{U} / \mathrm{ml})$. a Levels of nitric oxide in medium were determined by Griess reaction. b Cell death was determined using a cell death detection ELISA, corrected for DNA content in islets and expressed as fold-change compared with wild-type control. c Western blot was performed on protein extracts for PERK, JNK and EIF2 $\alpha$ phosphorylation (p) and CHOP. Total (t) JNK, EIF2 $\alpha$ and $\beta$-actin served as loading controls. Representative images are shown. Abundance of (d) pPERK, (e) pJNK1 (46 kDa), (f) pJNK2
(54 kDa), (g) pEIF2 $\alpha$ and (h) CHOP was quantified by densitometry and expressed as fold-change compared with wild-type control. i Total RNA was extracted and reverse-transcribed. Xbpl cDNA was amplified by PCR and digested with PstI, which cuts unprocessed $X b p 1$ into fragments. Processed (activated) $X b p 1$ lacks the restriction site and remains intact. Processed (intact) and unprocessed (cut) $\mathrm{Xbp} 1$ were quantified by densitometry. The value obtained for processed $X b p 1$ is expressed as a ratio of the total (processed+unprocessed) Xbpl mRNA level for each sample. These ratios are expressed as foldchange of the ratio in wild-type control islets. All results are mean \pm SEM determined from at least three experiments; ${ }^{*} p<0.05,{ }^{* *} p<0.01$ and $* * * p<0.001$ for cytokine effect in each genotype; ${ }^{\dagger} p<0.05,{ }^{\dagger \dagger} p<$ 0.01 and ${ }^{\dagger+} p<0.001$ for $i \mathrm{Nos}^{-1}{ }^{-1}$ islets vs wild-type islets mice (Fig. 5b). Thus, similar to the induction of ER stress above, the downregulation of Serca $2 b$ by cytokines appears to be mainly independent of nitric oxide formation.

\section{JNKactivityisrequiredforcytokine-inducedexpressionofChopand} Atf3inmouseislets Since our studies showed that cytokineinduced nitric oxide levels contribute to JNK2 activation (Fig. 3c, f), and also as previous studies have demonstrated that the JNK pathway can regulate Chop transcription in INS-1E beta cells [30], we tested whether JNK activity influences CHOP production in mouse islets. Nitric oxide production was unaffected by the inhibition of JNK activity (Fig. 6a). In negative control-treated mouse islets, the presence of IL- $1 \beta+$ IFN- $\gamma+$ TNF- $\alpha$ led to the expected increases in JNK1/2, c-JUN phosphorylation (Fig. 6b, ESM Fig. 2a-c) and CHOP production (Fig. 6b, c). In islets treated with JNK inhibitor, cytokine-induced JNK1/2 and cJUN phosphorylation was reduced (Fig. 6b, ESM Fig. 2a-c). JNK2 and c-JUN phosphorylation were significantly lower in the absence and presence of cytokine stimulation (Fig. 6b, 


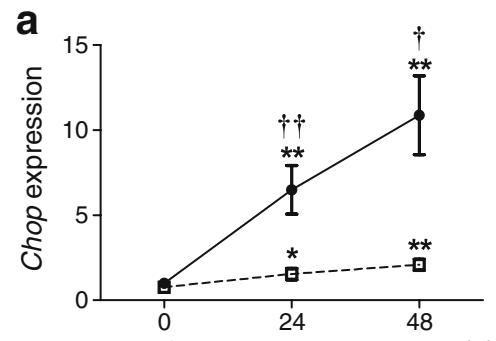

Time after cytokine stimulation (h)
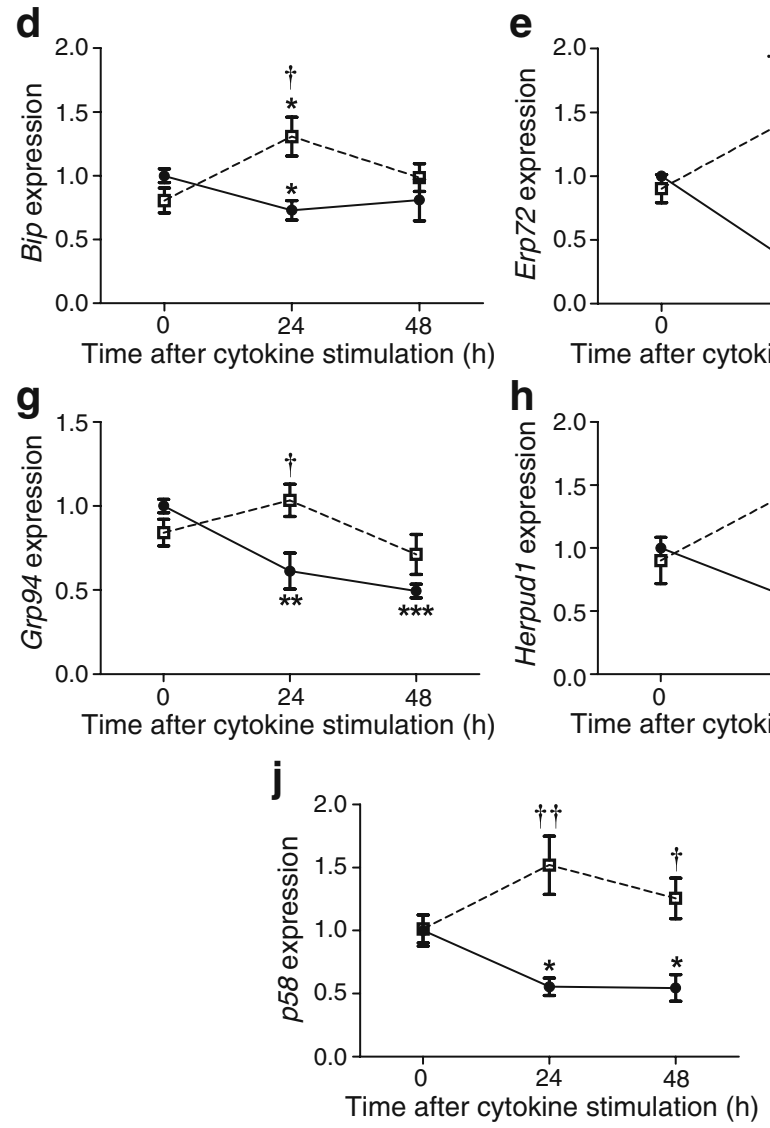

Fig. 4 Effects of $i$ Nos deletion on time-dependent changes in mRNA levels of UPR markers after cytokine stimulation of mouse islets. Isolated islets from wild-type (continuous lines) and $\mathrm{iNos}^{-/}$(dashed lines) mice were incubated for 0,24 and $48 \mathrm{~h}$ in the presence of IL-1 $\beta$ $(100 \mathrm{U} / \mathrm{ml}), \mathrm{IFN}-\gamma(250 \mathrm{U} / \mathrm{ml})$ and TNF- $\alpha(100 \mathrm{U} / \mathrm{ml})$. Total RNA was extracted, reverse-transcribed and analysed by real-time RT-PCR for (a) Chop, (b) Atf3, (c) Trib3, (d) Bip, (e) Erp72, (f) Fkbp11, (g) Grp94, (h)

ESM Fig. 2b, c), whereas JNK1 phosphorylation was only significantly reduced in the presence of cytokines (Fig. 6b, ESM Fig. 2a). Inhibition of JNK activity was associated with reduced CHOP production in the absence and presence of cytokine stimulation (Fig. 6b, c). By gene expression analysis, we found that, in addition to Chop, Atf 3 mRNA level was regulated by JNK signalling (Fig. 7). This indicates that JNK signalling is necessary for the cytokine-mediated increase in expression of Chop and Atf 3 ; and that even in the presence of nitric oxide, the induction of these genes in mouse islets is impaired by JNK inhibition.
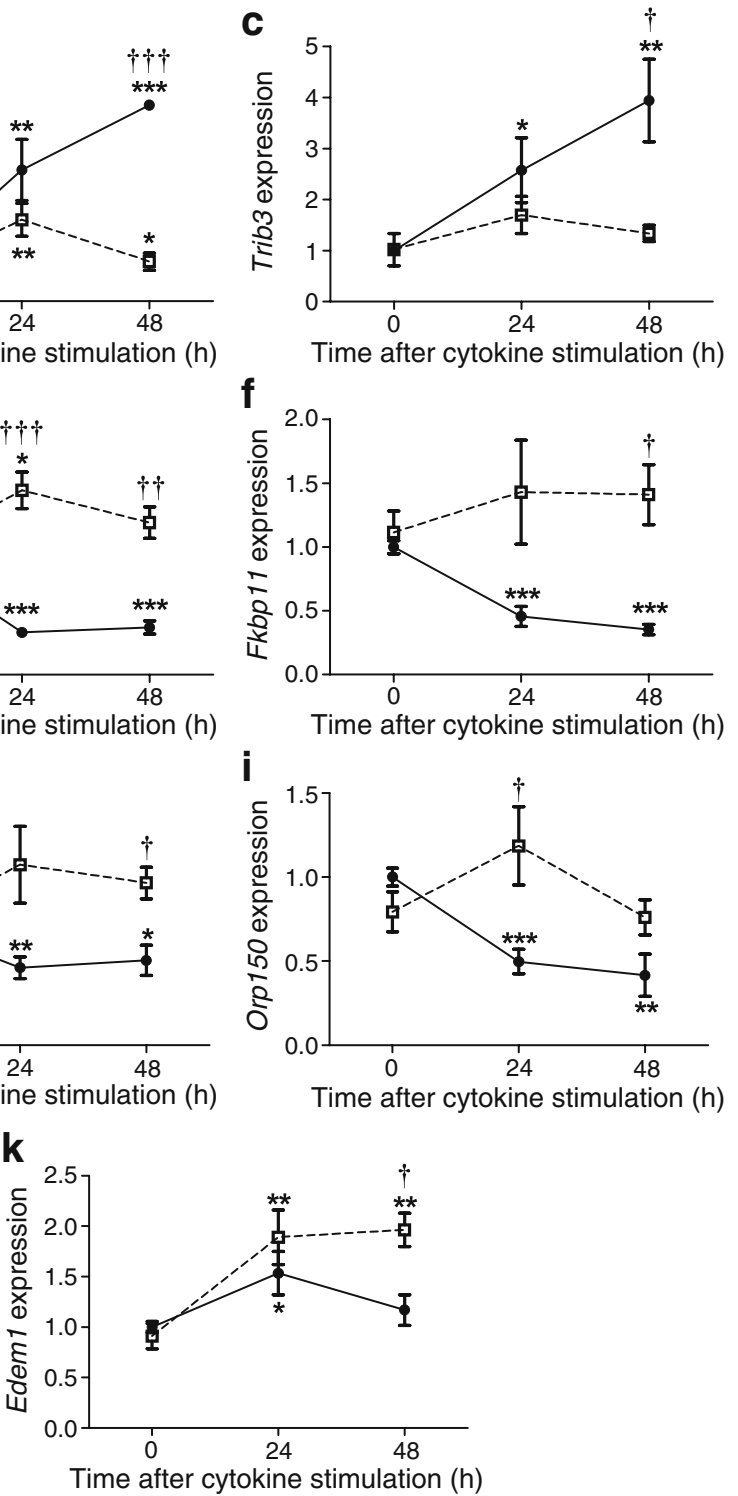

Herpud1, (i) Orp150, (j) p58 and (k) Edem1. All results are mean \pm SEM determined from at least three experiments and expressed as foldchange compared with wild-type control islets; ${ }^{*} p<0.05, * * p<0.01$ and ${ }^{* * *} p<0.001$ for cytokine effect in each genotype; ${ }^{\dagger} p<0.05,{ }^{\dagger} p<0.01$ and ${ }^{\dagger \dagger} p<0.001$ for $i \mathrm{Nos}^{-/-}$islets vs wild-type islets at the same time point

\section{Discussion}

The mechanisms by which inflammatory cytokines and the toxic free radical nitric oxide lead to beta cell failure in type 1 diabetes have been the subject of much recent attention. Previous studies have proposed that nitric oxide downregulates Serca2b expression, depleting ER calcium stores, and causing subsequent ER stress and apoptosis through the ER stress pathway [4-6]. Here, we tested whether nitric oxide makes a necessary contribution to cytokine-induced ER stress. We report that islets from $i \mathrm{Nos}^{-/-}$mice failed to 

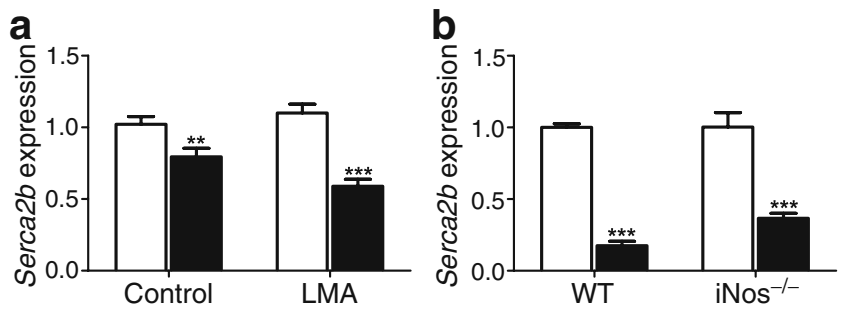

Fig. 5 Effects of iNOS inhibition on cytokine-mediated changes in Serca $2 b$ mRNA levels in MIN6 beta cells (a) and mouse islets (b). a MIN6 cells were incubated in the absence or presence of LMA $(1 \mathrm{mmol} / \mathrm{l})$ as indicated. MIN6 cells and (b) isolated islets from wildtype (WT) and $\mathrm{iNos}^{-/}$mice were incubated for $24 \mathrm{~h}$ in the absence (white bars) or presence (black bars) of IL-1 $\beta$ (100 U/ml), IFN- $\gamma$ $(250 \mathrm{U} / \mathrm{ml})$ and TNF- $\alpha(100 \mathrm{U} / \mathrm{ml})$. Total RNA was extracted, reversetranscribed and analysed by real-time RT-PCR. All results are mean \pm SEM determined from at least three experiments and expressed as fold-change compared with control; ${ }^{* *} p<0.01$ and ${ }^{* * *} p<0.001$ for cytokine effect in each treatment group or genotype

produce nitric oxide upon cytokine exposure, yet displayed increased PERK phosphorylation and Xbp1 splicing, which are entirely dependent on the activation of ER stress. Moreover, molecular and chemical inhibition of nitric oxide production failed to prevent cytokine-mediated downregulation of Serca2b expression in islets and MIN6 beta cells, inferring that the mechanism by which cytokines induce ER stress, through ER calcium dysregulation does not require nitric oxide. Thus, our studies clearly demonstrate that cytokines lead to downregulation of Serca2b and subsequent activation of ER stress in beta cells via mechanisms that are independent of nitric oxide formation. Notwithstanding this, we also demonstrated that nitric oxide plays a critical role in cellular responses to ER stress by differentially regulating adaptive and pro-apoptotic UPR signalling.
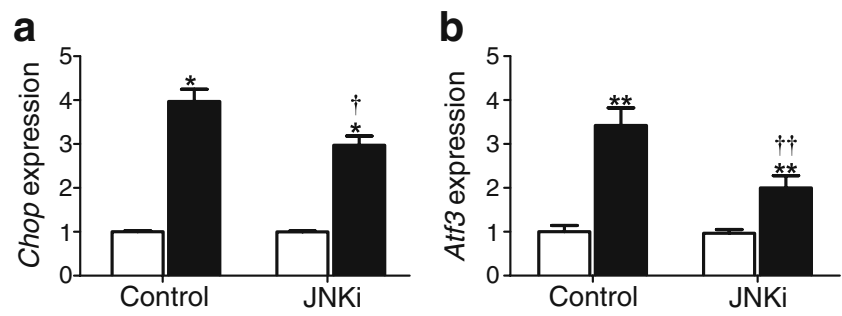

Fig. 7 Effects of JNK inhibition on cytokine-mediated changes in Chop (a) and Atf3 (b) mRNA levels in mouse islets. Isolated mouse islets were incubated for $24 \mathrm{~h}$ with JNK inhibitor (JNKi, $20 \mu \mathrm{mol} / \mathrm{l}$ ) or negative control (Control) as indicated, in combination with absence (white bars) or presence (black bars) of IL-1 $\beta$ (100 U/ml), IFN- $\gamma$ $(250 \mathrm{U} / \mathrm{ml})$ and TNF- $\alpha(100 \mathrm{U} / \mathrm{ml})$. Total RNA was extracted, reversetranscribed and analysed by real-time RT-PCR. All results are mean \pm SEM determined from at least three experiments and expressed as fold-change compared with control. ${ }^{*} p<0.05$ and $* * p<0.01$ for cytokine effect in each treatment group; ${ }^{\dagger} p<0.05$ and ${ }^{\dagger \dagger} p<0.01$ for JNKi vs negative control

Under ER stress conditions, cell fate depends on the balance between the death and survival components of the UPR. Inhibition of nitric oxide production in mouse islets: (1) prevented cytokine-mediated upregulation of proapopototic UPR genes Chop, Atf 3 and Trib3; and (2) relieved the cytokine-mediated suppression of ER chaperones, foldases and degradation enhancers. This alteration in the pattern of UPR signalling towards pro-survival gene expression was associated with reduced beta cell death in islets from $\mathrm{iNos}^{--}$mice. Further analysis showed that cytokines regulate Chop and Atf3 expression by controlling JNK activity. Since others [27] and we (Fig. 3) have shown that nitric oxide potentiates cytokine-induced JNK signalling, our data provide further insight into the complex signalling events in beta cells upon cytokine stimulation, with nitric

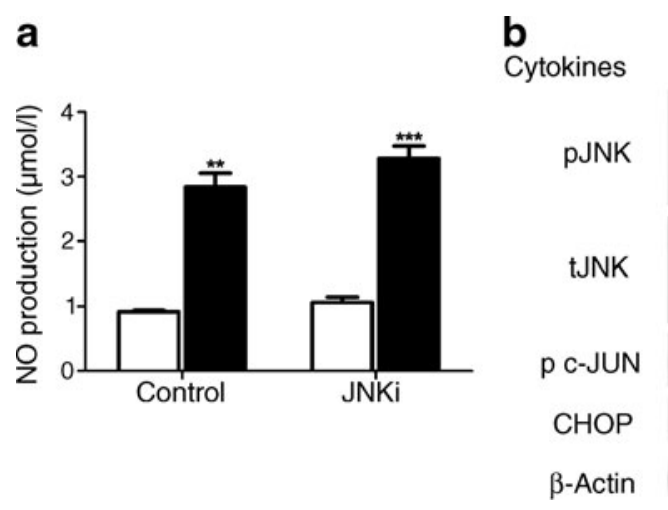

Fig. 6 Effects of JNK inhibition on cytokine-mediated changes in nitric oxide production and CHOP abundance in mouse islets. Isolated mouse islets were incubated for $24 \mathrm{~h}$ with $\mathrm{JNK}$ inhibitor (JNKi, $20 \mu \mathrm{mol} / \mathrm{l}$ ) or negative control (control) as indicated, in combination with absence (white bars) or presence (black bars) of IL-1 $\beta(100 \mathrm{U} / \mathrm{ml})$, IFN- $\gamma(250 \mathrm{U} / \mathrm{ml})$ and TNF- $\alpha(100 \mathrm{U} / \mathrm{ml})$. a Levels of nitric oxide in media were determined by Griess reaction. b Western blot was performed on protein extracts for JNK and c-JUN phosphorylation (p) and CHOP. Total (t) JNK and $\beta$-actin served as loading controls. Representative images are shown. c Abundance of CHOP was quantified by densitometry and expressed as fold-change compared with control untreated islets. All results are mean \pm SEM determined from at least three experiments; $* * p<0.01$ and $* * * p<0.001$ for cytokine effect in each treatment group; ${ }^{\dagger} p<0.05$ and ${ }^{\dagger \dagger} p<0.01$ for JNKi vs negative control 
oxide potentially representing an important factor that regulates the switch from survival to death UPR signalling.

The signalling molecules/mechanisms responsible for the generation of ER stress in beta cells probably differ depending on the stimulus. With lipid overload, several mechanisms have been proposed, including defective protein processing [31] and trafficking [32], and ER calcium dysregulation [33], each of which is thought to be independent of nitric oxide production. Importantly, the current study demonstrates that cytokines can also generate ER stress independently of nitric oxide production. These findings are in opposition to results from a previous study showing that cytokines induce $X b p 1$ splicing and reduce Serca2b expression via nitric oxide formation [5]. This discrepancy is possibly due to species differences (the previous study used rat vs our use of mouse beta cells) or different experimental conditions (the previous study adopted chemical inhibition of nitric oxide production only, vs our use of molecular and chemical iNOS disruption). However, our findings agree with the previous demonstration of the need for nitric oxide in cytokine-induced CHOP production [5]. Here, we extend these findings, demonstrating that nitric oxide more broadly and differentially regulates downstream pro-apoptotic and adaptive UPR signalling. Our data suggest that nitric oxide production plays a causal role in the atypical response of beta cells to ER stress induced by cytokines, in which adaptive UPR gene expression is suppressed and pro-apoptotic gene expression is readily activated.

Our studies demonstrate that nitric oxide exerts an inhibitory effect on a key transcriptional mediator in UPR signalling, XBP1. Since XBP1 promotes expression of adaptive UPR genes [28, 29], we speculate that nitric oxide-dependent restraint of XBP1 activation leads to cytokine-mediated downregulation of ER chaperones, foldases and degradation enhancers. This observation may also explain our previous observations of reduced $\mathrm{Xbpl}$ splicing and adaptive UPR gene expression in cytokinetreated INS- 1 cells and in islets from NOD mice [9]. On the other hand, our studies here demonstrated that nitric oxide is required for the potentiation of cytokine-stimulated JNK2 activation. The possibility that this may contribute to maintenance of the pro-apoptotic UPR signalling induced by cytokines is supported by the demonstration that JNK activity is required in cytokine-induced Chop promoter activation [30] and CHOP protein production (Fig. 6). This could explain the observed dissociation between PERK activation and CHOP induction. Other factors, in addition to JNK2 and XBP1, may also be involved, and further work will be required to determine the molecular mechanisms by which nitric oxide regulates the pattern of downstream proapoptotic and adaptive UPR gene expression. Possible mechanisms by which nitric oxide mediates its effects include regulation of transcription factors, gene transcription and mRNA stability, as well as targeted protein modifications by post-translational $S$-nitrosylation $[34,35]$.

The question of whether ER stress is a direct cause of cytokine-induced apoptosis and beta cell loss in type 1 diabetes is controversial $[7,9,36]$. One possible explanation for the contradictory findings in this area of research lies in the complexity of cytokine signalling. Cytokines activate an array of diverse ER stress-dependent and -independent death-related gene networks [37]. Thus, cytokines may induce apoptosis via multiple parallel and/or interacting pathways, which potentially involve activation of CHOP [4], ATF3 [38], tribbles homologue 3, nuclear factor $\mathrm{kB}$ [39], signal transducer and activator of transcription $1[40,41]$, DP5 [10], JNK [27, 42] or other components of the mitogenactivated protein kinase signalling pathway $[1,43,44]$. The predominant pathway of killing may depend on the nature of the cytokine stimulus and on critical interactions with antiapoptotic proteins of the B cell leukaemia/lymphoma 2 family, including myeloid cell leukaemia sequence 1 [11]. Additional studies are required to clarify the role of ER stress in cytokine-mediated beta cell failure in type 1 diabetes.

In summary, our studies suggest important modifications to the current model whereby cytokines induce ER stress and regulate the UPR in beta cells. These modifications are: (1) ER stress as such is generated independently of nitric oxide production; and (2) the pattern of downstream UPR signalling is regulated by nitric oxide production. The widespread differential regulation of adaptive and pro-apoptotic UPR gene expression by nitric oxide may provide a mechanism for the propensity of cytokine-stimulated beta cells to commit to cell death without an attempt to adapt to ER stress.

Acknowledgements This work was supported by grants from the Juvenile Diabetes Research Foundation and the National Health and Medical Research Council (NHMRC) of Australia.

Duality of interest The authors declare that there is no duality of interest associated with this manuscript.

\section{References}

1. Thomas HE, McKenzie MD, Angstetra E, Campbell PD, Kay TW (2009) Beta cell apoptosis in diabetes. Apoptosis 14:1389-1404

2. Rabinovitch A, Suarez-Pinzon WL (2003) Role of cytokines in the pathogenesis of autoimmune diabetes mellitus. Rev Endocr Metab Disord 4:291-299

3. Eizirik DL, Colli ML, Ortis F (2009) The role of inflammation in insulitis and beta-cell loss in type 1 diabetes. Nat Rev Endocrinol 5:219-226

4. Oyadomari S, Takeda K, Takiguchi M et al (2001) Nitric oxideinduced apoptosis in pancreatic beta cells is mediated by the endoplasmic reticulum stress pathway. Proc Natl Acad Sci USA 98:10845-10850 
5. Cardozo AK, Ortis F, Storling J et al (2005) Cytokines downregulate the sarcoendoplasmic reticulum pump Ca2+ ATPase $2 b$ and deplete endoplasmic reticulum $\mathrm{Ca}_{2}{ }^{+}$, leading to induction of endoplasmic reticulum stress in pancreatic beta-cells. Diabetes $54: 452-461$

6. Kharroubi I, Ladriere L, Cardozo AK, Dogusan Z, Cnop M, Eizirik DL (2004) Free fatty acids and cytokines induce pancreatic beta-cell apoptosis by different mechanisms: role of nuclear factor-kappaB and endoplasmic reticulum stress. Endocrinology 145:5087-5096

7. Chambers KT, Unverferth JA, Weber SM, Wek RC, Urano F, Corbett JA (2008) The role of nitric oxide and the unfolded protein response in cytokine-induced beta-cell death. Diabetes $57: 124-132$

8. Eizirik DL, Cardozo AK, Cnop M (2008) The role for endoplasmic reticulum stress in diabetes mellitus. Endocr Rev 29:42-61

9. Akerfeldt MC, Howes J, Chan JY et al (2008) Cytokine-induced beta-cell death is independent of endoplasmic reticulum stress signaling. Diabetes 57:3034-3044

10. Gurzov EN, Ortis F, Cunha DA et al (2009) Signaling by IL-1beta +IFN-gamma and ER stress converge on DP5/Hrk activation: a novel mechanism for pancreatic beta-cell apoptosis. Cell Death Differ 16:1539-1550

11. Allagnat F, Cunha D, Moore F, Vanderwinden JM, Eizirik DL, Cardozo AK (2011) Mcl-1 downregulation by pro-inflammatory cytokines and palmitate is an early event contributing to beta-cell apoptosis. Cell Death Differ 18:328-337

12. Tonnesen MF, Grunnet LG, Friberg J et al (2009) Inhibition of nuclear factor-kappaB or Bax prevents endoplasmic reticulum stress- but not nitric oxide-mediated apoptosis in INS-1E cells. Endocrinology 150:4094-4103

13. Gurzov EN, Ortis F, Bakiri L, Wagner EF, Eizirik DL (2008) JunB inhibits ER stress and apoptosis in pancreatic beta cells. PLoS ONE 3:e3030

14. Allagnat F, Christulia F, Ortis F et al (2010) Sustained production of spliced X-box binding protein 1 (XBP1) induces pancreatic beta cell dysfunction and apoptosis. Diabetologia 53:1120-1130

15. Weber SM, Chambers KT, Bensch KG, Scarim AL, Corbett JA (2004) PPARgamma ligands induce ER stress in pancreatic betacells: ER stress activation results in attenuation of cytokine signaling. Am J Physiol Endocrinol Metab 287:E1171-E1177

16. Ron D, Walter P (2007) Signal integration in the endoplasmic reticulum unfolded protein response. Nat Rev Mol Cell Biol 8:519-529

17. Wu J, Kaufman RJ (2006) From acute ER stress to physiological roles of the unfolded protein response. Cell Death Differ 13:374-384

18. Urano F, Wang X, Bertolotti A et al (2000) Coupling of stress in the ER to activation of JNK protein kinases by transmembrane protein kinase IRE1. Science 287:664-666

19. Oyadomari S, Koizumi A, Takeda K et al (2002) Targeted disruption of the Chop gene delays endoplasmic reticulum stress-mediated diabetes. J Clin Invest 109:525-532

20. Song B, Scheuner D, Ron D, Pennathur S, Kaufman RJ (2008) Chop deletion reduces oxidative stress, improves beta cell function, and promotes cell survival in multiple mouse models of diabetes. J Clin Invest 118:3378-3389

21. Laybutt DR, Preston AM, Akerfeldt MC et al (2007) Endoplasmic reticulum stress contributes to beta cell apoptosis in type 2 diabetes. Diabetologia 50:752-763

22. Pirot P, Eizirik DL, Cardozo AK (2006) Interferon-gamma potentiates endoplasmic reticulum stress-induced death by reducing pancreatic beta cell defence mechanisms. Diabetologia 49:1229-1236
23. Hevel JM, Marletta MA (1994) Nitric-oxide synthase assays. Methods Enzymol 233:250-258

24. Busch AK, Gurisik E, Cordery DV et al (2005) Increased fatty acid desaturation and enhanced expression of stearoyl coenzyme A desaturase protects pancreatic beta-cells from lipoapoptosis. Diabetes 54:2917-2924

25. Kjorholt C, Akerfeldt MC, Biden TJ, Laybutt DR (2005) Chronic hyperglycemia, independent of plasma lipid levels, is sufficient for the loss of beta-cell differentiation and secretory function in the $\mathrm{db} / \mathrm{db}$ mouse model of diabetes. Diabetes $54: 2755-2763$

26. Calfon M, Zeng H, Urano $F$ et al (2002) IRE1 couples endoplasmic reticulum load to secretory capacity by processing the XBP-1 mRNA. Nature 415:92-96

27. Storling J, Binzer J, Andersson AK et al (2005) Nitric oxide contributes to cytokine-induced apoptosis in pancreatic beta cells via potentiation of JNK activity and inhibition of Akt. Diabetologia 48:2039-2050

28. Yoshida H, Matsui T, Hosokawa N, Kaufman RJ, Nagata K, Mori $\mathrm{K}$ (2003) A time-dependent phase shift in the mammalian unfolded protein response. Dev Cell 4:265-271

29. Lee AH, Iwakoshi NN, Glimcher LH (2003) XBP-1 regulates a subset of endoplasmic reticulum resident chaperone genes in the unfolded protein response. Mol Cell Biol 23:7448-7459

30. Pirot P, Ortis F, Cnop M et al (2007) Transcriptional regulation of the endoplasmic reticulum stress gene chop in pancreatic insulinproducing cells. Diabetes 56:1069-1077

31. Jeffrey KD, Alejandro EU, Luciani DS et al (2008) Carboxypeptidase E mediates palmitate-induced beta-cell ER stress and apoptosis. Proc Natl Acad Sci USA 105:8452-8457

32. Preston AM, Gurisik E, Bartley C, Laybutt DR, Biden TJ (2009) Reduced endoplasmic reticulum (ER)-to-Golgi protein trafficking contributes to ER stress in lipotoxic mouse beta cells by promoting protein overload. Diabetologia 52:2369 2373

33. Cunha DA, Hekerman P, Ladriere L et al (2008) Initiation and execution of lipotoxic ER stress in pancreatic beta-cells. J Cell Sci 121:2308-2318

34. Bogdan C (2001) Nitric oxide and the regulation of gene expression. Trends Cell Biol 11:66-75

35. Derakhshan B, Hao G, Gross SS (2007) Balancing reactivity against selectivity: the evolution of protein S-nitrosylation as an effector of cell signaling by nitric oxide. Cardiovasc Res 75:210-219

36. Huang CJ, Lin CY, Haataja L et al (2007) High expression rates of human islet amyloid polypeptide induce endoplasmic reticulum stress mediated beta-cell apoptosis, a characteristic of humans with type 2 but not type 1 diabetes. Diabetes 56:2016-2027

37. Ortis F, Naamane N, Flamez D et al (2010) Cytokines interleukin1 beta and tumor necrosis factor-alpha regulate different transcriptional and alternative splicing networks in primary beta-cells. Diabetes 59:358-374

38. Hartman MG, Lu D, Kim ML et al (2004) Role for activating transcription factor 3 in stress-induced beta-cell apoptosis. Mol Cell Biol 24:5721-5732

39. Eldor R, Yeffet A, Baum K et al (2006) Conditional and specific NF-kappaB blockade protects pancreatic beta cells from diabetogenic agents. Proc Natl Acad Sci USA 103:5072-5077

40. Gysemans CA, Ladriere L, Callewaert H et al (2005) Disruption of the gamma-interferon signaling pathway at the level of signal transducer and activator of transcription-1 prevents immune destruction of beta-cells. Diabetes 54:23962403

41. Moore F, Naamane N, Colli ML et al (2011) STAT1 is a master regulator of pancreatic beta cells apoptosis and islet inflammation. J Biol Chem 286:929-941 
42. Ammendrup A, Maillard A, Nielsen K et al (2000) The c-Jun amino-terminal kinase pathway is preferentially activated by interleukin-1 and controls apoptosis in differentiating pancreatic beta-cells. Diabetes 49:1468-1476

43. Mokhtari D, Myers JW, Welsh N (2008) MAPK kinase kinase-1 is essential for cytokine-induced c-Jun NH2-terminal kinase and nuclear factor-kappaB activation in human pancreatic islet cells. Diabetes 57:1896-1904

44. Larsen L, Storling J, Darville M et al (2005) Extracellular signalregulated kinase is essential for interleukin-1-induced and nuclear factor kappaB-mediated gene expression in insulin-producing INS-1E cells. Diabetologia 48:2582-2590 